\title{
Anterior Segment Optical Coherence Tomography and its Clinical Applications in Glaucoma
}

\author{
${ }^{1}$ Haitao Li, ${ }^{2}$ Vishal Jhanji, ${ }^{3}$ Syril Dorairaj, ${ }^{4}$ Andrea Liu, ${ }^{5}$ Dennis SC Lam, ${ }^{6}$ Christopher K Leung
}

\begin{abstract}
Anterior segment optical coherence tomography (ASOCT) is an imaging modality that provides both quantitative and qualitative information on the cornea, anterior chamber angle, iris and crystalline lens. ASOCT shows excellent repeatability and reproducibility for the measurement of corneal thickness, anterior chamber angle and anterior chamber depth. With realtime video recording, ASOCT can also effectively capture the dynamic changes of the iris and lens in response to light and eye accommodation. With this additional information, physiological and pathological changes of the anterior segment structures are now better understood. This article aims to provide an overview of the current applications of ASOCT in glaucoma.
\end{abstract}

Keywords: Optical coherence tomography, Anterior segment, Anterior chamber angle.

How to cite this article: Li H, Jhanji V, Dorairaj S, Liu A, Lam DSC, Leung CK. Anterior Segment Optical Coherence Tomography and its Clinical Applications in Glaucoma. J Current Glau Prac 2012;6(2):68-74.

Source of support: Nil

Conflict of interest: None declared

\section{INTRODUCTION}

Assessment of the anterior segment is an integral part of ophthalmic examination. Traditionally, the anterior segment and iridocorneal angle are evaluated with the help of a slit lamp and gonioscope. With the advancement of technology, low coherence interferometry was developed, upon which optical coherence tomography (OCT) is based. OCT provides multiple detailed cross-sectional images of the internal structures in biological tissues. Currently, two anterior segment OCT (AS-OCT) models are commercially available-the Visante OCT (Carl Zeiss Meditec, Dublin CA, USA) and the slit-lamp OCT (SLOCT) (Heidelberg Engineering, GmbH, Dossenheim, Germany). Since their availability, noninvasive studies of the structures and pathologies of the anterior segment have been made possible. This article serves to highlight the principles and clinical applications of ASOCT in glaucoma.

\section{PRINCIPLES OF AS-OCT}

The commercially available OCT system, also known as time-domain OCT (TD-OCT), was first described in 1991 by Huang et al. ${ }^{1}$ The principle of OCT imaging is based on the measurement of delay in light reflected from various tissue structures. Low coherence infrared light is split by the beam splitter of a Michelson interferometer into two components - one is directed to a movable mirror in the reference arm and the other to the object of interest in the sample arm. The reflected signals from these two components are then superimposed at the interferometer. The strength of each reflected signal is a function of depth in each scan.

Ophthalmic OCT was initially developed for retinal imaging and used a near-infrared $800 \mathrm{~nm}$ superluminescent diode (SLD) as the light emitting source. This OCT model was subsequently applied to anterior segment imaging, capturing images of the cornea, anterior chamber angle, iris and crystalline lens. ${ }^{2-7}$ However, this type of OCT was limited by its light source and imaging speed (400 A-scans per second). This shortcoming prevents the light beam from penetrating the limbus and other opaque structures. ${ }^{3}$ To overcome this drawback, AS-OCT, specially designed for anterior segment imaging was developed. This new model employs an SLD of a longer wavelength $(1310 \mathrm{~nm})$. With the use of this model, about $90 \%$ of the $1310 \mathrm{~nm}$ light is absorbed by the ocular media before hitting the retina, allowing us to use light that is 20 times stronger before reaching the retinal exposure limit. With the improvements in speed and light penetration, the entire anterior segment can now be captured in one frame, in 0.125 seconds and in $18 \mu \mathrm{m}$ resolution (Visante ${ }^{\mathrm{TM}} \mathrm{OCT}$ User Manual, 2006). However, the ciliary body is still poorly visualized owing to the pigmented posterior layer of the iris which hinders light penetration. ${ }^{8,9}$

Inspite of all the above-mentioned advantages, TDOCT is relatively time-consuming mainly due to its sliding a mirror along the reference arm. Currently, the fastest commercial TD-OCT system is the Visante anterior segment OCT (Carl Zeiss Meditec, Inc, Dublin, CA), which acquires $2000 \mathrm{~A}$-scans per second. With the introduction of the Fourier domain OCT (FD-OCT), ocular imaging can be performed at a higher speed and at a higher resolution. ${ }^{10-12}$ The stated axial resolution of FD-OCT ranges from 4 to $7 \mu \mathrm{m}$. Some of the food and drug administration (FDA)approved commercially available spectral domain OCT machines became available at the end of year 2006 and include the following: RTVue (Optovue Inc, Fremont, California), Cirrus HD-OCT (Carl Zeiss Meditec Inc, Dublin, California), Spectralis (Heidelberg Engineering Inc, Heidelberg, Germany), SOCT Copernicus (Optopol Technology, Zawiercie, Poland) and 3D OCT-1000 (Topcon, Paramus, New Jersey). 


\section{AS-OCT MODELS}

At present, two AS-OCT models are commercially available (Table 1) - the ZEISS Visante ${ }^{\text {TM }}$ OCT Model 1000 (Visante OCT) (Carl Zeiss Meditec, Dublin CA, USA) and the SlitLamp OCT (SLOCT) (Heidelberg Engineering, GmbH, Dossenheim, Germany). Both equipped with a $1310 \mathrm{~nm}$ SLD, they provide rapid, noninvasive imaging of the anterior segment with the patient in upright position.

\section{ZEISS Visante ${ }^{\text {TM }}$ OCT Model 1000 (Visante OCT)}

The Visante OCT is a standalone machine and was approved by the FDA in September 2005. Its scan rate reaches up to 2048 A-scans per second and its axial and transverse image resolutions are up to 18 and $60 \mu \mathrm{m}$. (Visante ${ }^{\mathrm{TM}}$ OCT User Manual, 2006). The Visante OCT can be easily operated and does not require much experience for image acquisition.

The Visante ASOCT machine can be operated in various modes, each of which is configured for a specific application, e.g. cornea, anterior chamber biometry. To further its technological superiority, calculations of the depth and width of anterior chamber and anterior chamber angle (ACA) can all be done automatically or manually by the caliper tools provided.

\section{Slit-lamp OCT (SLOCT)}

The SLOCT is essentially an OCT incorporated with HaagStreit slit-lamp biomicroscopy (SLOCT User Manual,
2006). Its axial and transverse resolutions are $25 \mu \mathrm{m}$ and 20 to $100 \mu \mathrm{m}$, respectively (SLOCT Operation Manual, 2006). Parameters including the central corneal thickness (CCT), the central anterior chamber depth (ACD) and the anterior chamber volume (ACV) can all be determined automatically. After manual location of the scleral spur, the interscleral spur distance, angle opening distance (AOD 500, AOD 750), trabecular-iris spur area (TISA 500, TISA 750), trabecular-iris angle (TIA 750) and the scleral spur-to-scleral spur distance are measured semiautomatically.

\section{CLINICAL APPLICATIONS OF ASOCT}

\section{Imaging of Anterior Chamber}

\section{Anterior Chamber Angle (ACA)}

Primary angle closure is the leading cause of glaucomainduced blindness in the East Asian population. ${ }^{13}$ Evaluation of the width of the ACA and its inlet during the ophthalmic examination is essential to determining the susceptibility of the angle to close (Fig. 1). Although gonioscopy is the current reference standard in ACA assessment, its drawbacks include its subjective and semiquantitative results, its need for illumination, its dependence on the operator and its inability to delineate the angle configuration when the goniolens is in direct contact with the cornea. ${ }^{14,15}$ Quantitative assessment of the ACA was first described by Pavlin and Foster in ultrsound biomicroscopy (UBM)

Table 1: Summary of system features of the Visante OCT and SLOCT

\begin{tabular}{|c|c|c|c|}
\hline & Items & Visante OCT & SLOCT \\
\hline Light & Laser source & SLD & SLD \\
\hline Source & $\begin{array}{l}\text { Center wavelength } \\
\text { Spectral bandwidth } \\
\text { Optical power }\end{array}$ & $\begin{array}{l}1310 \mathrm{~nm} \\
\mathrm{~N} / \mathrm{A} \\
<6.5 \mathrm{~mW}\end{array}$ & $\begin{array}{l}1310 \mathrm{~nm} \\
50 \mathrm{~nm} \\
<0.2 \mathrm{~mW}\end{array}$ \\
\hline Resolution & $\begin{array}{l}\text { Axial resolution } \\
\text { Transverse resolution } \\
\text { Pixel resolution (transverse } \times \text { axial) } \\
\text { Signal-to-noise ratio }\end{array}$ & $\begin{array}{c}\sim 18 \mu \mathrm{m} \\
\sim 60 \mu \mathrm{m} \\
256 \sim 512 \times 1024 \\
\text { N/A }\end{array}$ & $\begin{array}{l}\sim 25 \mu \mathrm{m} \\
20-100 \mu \mathrm{m} \\
215 \text { in axial } \\
>90 \mathrm{~dB}\end{array}$ \\
\hline Scan speed & $\begin{array}{l}\text { A scan frequency }(\mathrm{Hz}) \\
\text { A scan number/line } \\
\text { OCT frames/second }\end{array}$ & $\begin{array}{c}2048 \\
256 \\
8\end{array}$ & $\begin{array}{c}200 \\
215 \\
1\end{array}$ \\
\hline Penetration & $\begin{array}{l}\text { Opaque media } \\
\text { Limbus, sclera } \\
\text { Ciliary sulcus visible } \\
\text { Zonule visible }\end{array}$ & $\begin{array}{l}\text { Yes } \\
\text { Yes } \\
\text { No } \\
\text { No }\end{array}$ & $\begin{array}{l}\text { Yes } \\
\text { Yes } \\
\text { No } \\
\text { No }\end{array}$ \\
\hline Scan types & $\begin{array}{l}\text { Maximum scan width } \times \text { scan depth } \\
\text { Single scan } \\
\text { Dual and quadrant scans } \\
\text { Pachymetry map }\end{array}$ & $\begin{array}{c}16 \times 8 \mathrm{~mm} \\
\text { Yes } \\
\text { Yes } \\
\text { Yes (8 meridians) }\end{array}$ & $\begin{array}{l}15 \times 7 \mathrm{~mm} \\
\text { Yes } \\
\text { No } \\
\text { No }\end{array}$ \\
\hline Image & Eye contact & No & No \\
\hline Acquisition & $\begin{array}{l}\text { Eye movement monitoring } \\
\text { Real-time image } \\
\text { Internal fixation target } \\
\text { Fixation angle adjustment } \\
\text { Accommodation adjustment range }\end{array}$ & $\begin{array}{c}\text { Yes } \\
\text { Yes } \\
\text { Starburst pattern } \\
\text { Yes } \\
-35 \mathrm{D} \text { to }+20 \mathrm{D} \\
\end{array}$ & $\begin{array}{l}\text { Yes } \\
\text { Yes } \\
\text { No } \\
\text { No } \\
\text { No } \\
\end{array}$ \\
\hline
\end{tabular}

SLD: Superluminescent diode; N/A: Not available 


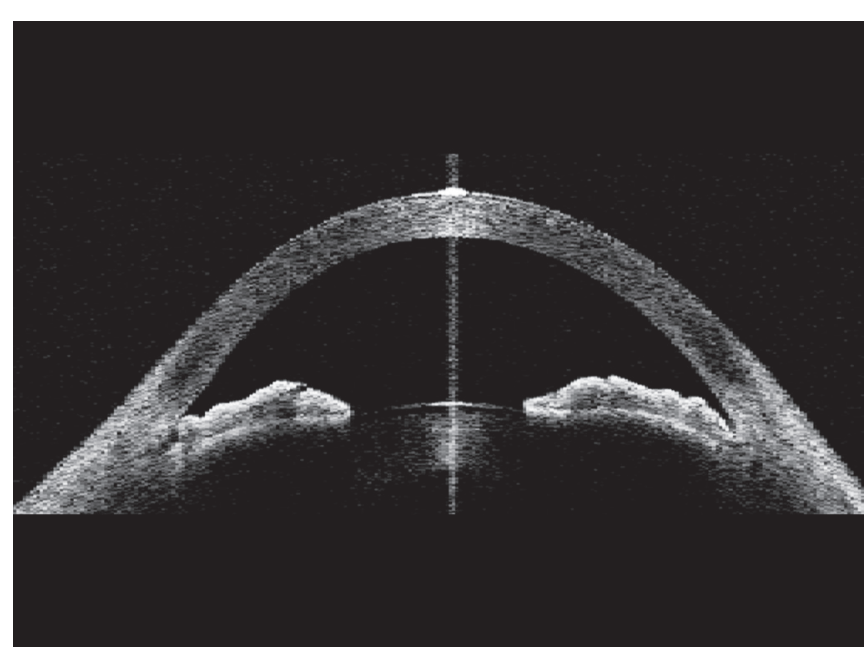

Fig. 1: Iris configuration in narrow angles: Convex configuration or anterior bowing of iris is visualized in one frame
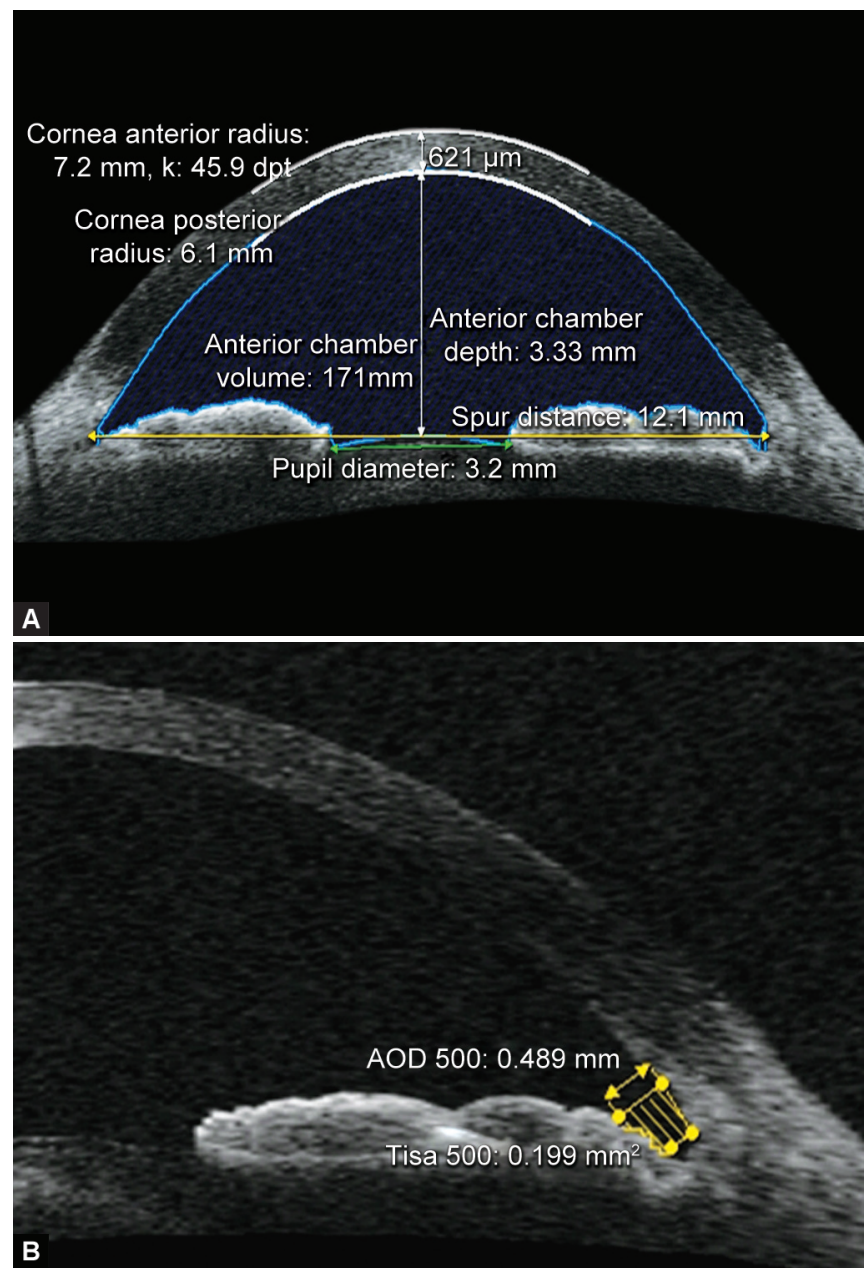

Figs 2A and B: (A) Measurement of chamber parameters using AS-OCT: Anterior chamber depth and volume can be measured using AS-OCT. (B) AOD500 (angle opening distance at $500 \mu \mathrm{m}$ from the scleral spur), TISA500 (trabecular-iris space area at 500 $\mu \mathrm{m}$ from the scleral spur), and TIA500 (trabecular-iris angle at 500 $\mu \mathrm{m}$ from the scleral spur) can be measured using AS-OCT

imaging. ${ }^{16}$ The most important parameters are the angle opening distance (AOD) and the trabecular-iris angle (TIA) (Fig. 2B). AOD is defined as the length of the line drawn from the point on the endothelial surface $500 \mu \mathrm{m}$ or
$750 \mu \mathrm{m}$ (AOD 500, AOD 750) anterior to the scleral spur to the iris surface perpendicular to the corneal endothelial surface. TIA is defined as an angle formed by the apex at the iris recess and the arms passing through the point on the meshwork $500 \mu \mathrm{m}$ or $750 \mu \mathrm{m}$ (TIA 500, TIA 750) from the scleral spur and the point on the iris perpendicularly opposite. Because the anterior iris surface profile may confound the measurement of the AOD/TIA, angle recess area (ARA) and trabecular-iris space area (TISA) were subsequently introduced by Ishikawa and Radhakrishnan, respectively. ${ }^{17,18}$ ARA is defined as a triangular area bordered by the anterior iris surface, corneal endothelium and a line perpendicular to the corneal endothelium drawn from a point $500 \mu \mathrm{m} / 750 \mu \mathrm{m}$ (ARA 500/ARA750) anterior to the scleral spur to the iris surface. ${ }^{17}$ The ARA is, theoretically, a better measurement parameter than the AOD because it takes into account the whole contour of the iris surface rather than measuring at a single point on the iris as is the case with the AOD. TISA is a new parameter proposed by Radhakishnan for quantitative measurement of the ACA. The defining boundaries for this trapezoidal area are as follows: anteriorly, the AOD 500 or AOD 750; posteriorly, a line drawn from the scleral spur perpendicular to the plane of the inner scleral wall to the opposing iris; superiorly, the inner corneoscleral wall; and inferiorly, the iris surface. ${ }^{18}$ This parameter represents the actual filtering area more accurately when compared with the ARA because the TISA excludes the nonfiltering region behind the scleral spur.

Although UBM offers tremendous insight into the anterior chamber angle configuration and allows detailed imaging of the ciliary body and the posterior chamber, it is limited by being a close-contact immersion technique (Table2). Inadvertent corneal indentation can cause artifacts, widening the angle measurement. ${ }^{17}$ With new ASOCT imaging techniques, detailed spatial relationships of the anterior segment structures can be visualized and objective ACA measurements can be performed in a non-contact manner. In addition, the use of infrared laser and real-time eye position monitor during examination permits the precise capture of angle morphology in the dark. With higher scan speed (8 frames/sec), SLOCT has the potential to provide valuable quantitative and spatial information regarding dynamic changes of the angle configuration which cannot be provided by standard gonioscopy and UBM.

\section{The Reliability of ACA Measurement}

Most of the important parameters for ACA quantitative measurement are based on the identification of the point of scleral spur. Reliable documentation of the angle dimensions is therefore dependent on precise and repeatable localization of the scleral spur. Sakata et al found that, on the same 
Table 2: Comparisons of ASOCT with ultrasound microscopy (UBM)

\begin{tabular}{lcc} 
& ASOCT & UBM \\
\hline Scan source & Infra-red light $(1310 \mathrm{~nm})$ & Ultrasound $(50 \sim 80 \mathrm{MHz})$ \\
No corneal indentation & Yes & No \\
Examination position & Sitting & Supine \\
Precise scanning & Yes & No \\
Imaging under dark & Yes & No \\
Internal fixation & Yes & 256 \\
A scans/line & 256 & $\sim 8$ \\
Scan speed (Frame/sec.) & $\sim 8$ & $\sim 25 \mu \mathrm{m}$ \\
Axial resolution $(\mu \mathrm{m})$ & $\sim 18$ & $\sim 50 \mu \mathrm{m}$ \\
Transverse resolution $(\mu \mathrm{m})$ & $\sim 60 \mu \mathrm{m}$ & $5.0 \times 5.0$ \\
Scan depth (mm) & $\sim 16.0 \times \sim 8.0$ & $16 \sim 18 \%$ \\
CVw for ACA measurement & $6 \sim 11 \%$ & Yes \\
Cillary body visualization & $\mathrm{No}$ & \\
& &
\end{tabular}

Visante OCT images, the intraobserver agreement in detecting the scleral spur (132 quadrants) was moderate to substantial with $\kappa=0.65 .{ }^{19}$ They also reported that, in the assessment of the exact scleral spur location, the distance between the scleral spur localized in the same image across 2 sessions was within $10 \mu \mathrm{m}$ in $83 \%$ of the 78 quadrants assessed and within $20 \mu \mathrm{m}$ in $90 \%$. The location of the scleral spur on ASOCT images was less detectable in quadrants with a closed angle on gonioscopy (odds ratio $=$ $0.54, \mathrm{p}=0.02$ ) and also in images obtained in the superior and inferior compared with the nasal and temporal quadrants $(64,67,75$ and $80 \%$ respectively; $p<0.001)$.

The differences in ACA measurements in different lighting conditions have been investigated with UBM and ASOCT. ${ }^{17,20,21}$ Leung et al also described the dynamic ACA changes induced by dark-light changes by Visante OCT through real-time video recording. ${ }^{22}$ They found that the AOD and TISA decreased linearly with increasing pupil size in most cases (85.5\% in AOD and $90.9 \%$ in TISA). It was estimated that for each mm change in pupil size, there was an average of $94 \mu \mathrm{m}$ change in the AOD 500 and $0.035 \mathrm{~mm}^{2}$ change in the TISA. Although significant differences of angle measurements were found between light and dark conditions, good repeatability and reproducibility was achieved as long as the lighting condition had been standardized by ASOCT with the intersession ICC for AOD and TIA measurements being higher than $0.91 .^{20,23}$ The intersession $\mathrm{CVw}$ for angle measurements by Visante OCT was less than that of UBM (Visante OCT: 6 11\%, UBM: 16 18\%). ${ }^{20,24}$

Significant correlations were found among ACA measurements by ASOCT, gonioscopy and UBM. ${ }^{25,26}$ In general, the correlation in detecting a closed ACA quadrant using ASOCT and gonioscopy was fair with a $\kappa$ of 0.4. But ASOCT tended to detect more closed angles than gonioscopy, particularly in the superior and inferior quadrants. ${ }^{19}$ There was no significant difference in angle measurements between ASOCT and UBM in either nasal or temporal quadrants, but a significant higher AOD measurement was observed by ASOCT in the superior and inferior angles compared with UBM. ${ }^{8,25}$ Of note, although SLOCT and Visante OCT generally had no significant difference in angle measurements, the two available ASOCT models had poor correlations in ACA measurement despite comparable pupil diameters obtained, with the spans of $95 \%$ LOA of the nasal/temporal angle measurements between them being $437 \mu \mathrm{m} / 531 \mu \mathrm{m}, 0.174 \mathrm{~mm}^{2} / 0.186 \mathrm{~mm}^{2}$, and $25.3^{\circ} / 28.0^{\circ}$ for AOD, TISA and TIA, respectively. ${ }^{27}$ The poor correlation is likely related to differences in the choice of refractive indexes in the calculation of anterior segment dimensions, algorithms for image dewarping, the exact scan locations and the state of accommodation.

Clinically, ASOCT has been applied to the observation of ACA change after glaucoma surgeries, such as laser peripheral iridotomy (LPI), argon laser peripheral iridoplasty (ALPI), trabeculectomy combined with cataract extraction and intraocular lens implantation, etc.

\section{Anterior Chamber Depth (ACD) and Anterior Cham- ber Volume (ACV)}

Shallow anterior chamber is regarded as a cardinal risk factor for primary angle closure and therefore, anterior chamber depth (ACD) (Fig. 2A) measurement has shown to be a promising screening parameter for angle closure. ${ }^{28}$ With both UBM and OCT, ACD is most often measured as the axial distance from the internal corneal surface to the lens surface. ${ }^{29}$ Using a prototype ASOCT, Baikoff observed that the ACD increased over the early years of life, peaking at around 15 to 20 years, then slowly decreasing until 80 years. ${ }^{30}$ Their results also showed that ACD reduced by a mean of $30 \mu \mathrm{m}$ with 1.0 diopter of accommodation.

Anterior chamber volume (ACV) (Fig. 2A) is another useful parameter for detecting individuals at risk of developing primary angle closure. ${ }^{31,32}$ Upon examination, the ASOCT proved to be reliable in ACV measurement with 
CVw less than $0.96 \% .{ }^{18,33}$ With the aid of Visante OCT, Lei et al observed that the ACV increased significantly from 73.86 to $84.14 \mu \mathrm{l}$ after laser peripheral iridotomy $(\mathrm{p}<0.001) .{ }^{34}$

\section{Imaging of Filtering Blebs}

Blebs imaging after trabeculectomy was first reported with UBM. ${ }^{35-37}$ Other methods of bleb imaging that have been reported in the past include in vivo confocal microscopy ${ }^{38}$ and AS-OCT. ${ }^{39,40}$ The noncontact nature of OCT imaging provides a much safer approach to examine the intrableb morphology (Fig. 3) in the early postoperative period, thereby offering a unique opportunity to study the healing and remodeling process inside the blebs longitudinally. ${ }^{38-42}$ Using ASOCT, four-different patterns of intrableb morphology, including diffuse filtering blebs, cystic blebs, encapsulated blebs and flattened blebs were identified and found to be closely related to slit-lamp appearance and bleb function. ${ }^{39}$ Combining both clinical and bleb imaging information could provide a new perspective toward understanding the different surgical outcomes after trabeculectomy. More recently, Singh et al have reported bleb morphology in patients using spectral domain OCT (Cirrus HD-OCT, Carl Zeiss Meditec Inc., Dublin, CA, USA). In this study the SD-OCT could reveal details of the bleb wall but could not image the deeper structures such as internal ostium or flap position. ${ }^{43}$

Tominaga et $\mathrm{al}^{44}$ assessed the postoperative filtering bleb function using AS-OCT. In this study the height and extent of the internal cavity and the bleb height were not correlated with the IOP. The mean IOP in eyes with a low-reflectivity bleb wall was significantly $(p=0.001)$ lower than in eyes with a high-reflectivity wall. The bleb wall thickness was negatively $(p=0.004)$ correlated with the IOP.

Pfenninger et $\mathrm{al}^{45}$ analyzed the morphology of filtering blebs shortly after trabeculectomy surgery using AS-OCT. They found that the internal reflectivity of the fluid-filled cavity of the filtering bleb correlated very well to the IOP with $\mathrm{R}(2)=0.3762, \mathrm{p}<0.0001$. This study may have future impact in evaluating the postoperative success or failure of filtering blebs.

Other conditions cyclodialysis cleft: In ocular trauma and in postoperative period, AS-OCT (Fig. 4) should be kept in mind for evaluating any trauma/postoperative-associated changes in ocular anatomy. Cyclodialysis is a separation of the longitudinal muscles of the ciliary body from the scleral spur and is often accompanied by a supraciliary effusion.

Glaucoma drainage implants: The position, patency and course of drainage tubes can be ascertained using AS-OCT (Fig. 5) ASOCT would be especially helpful in assessing the

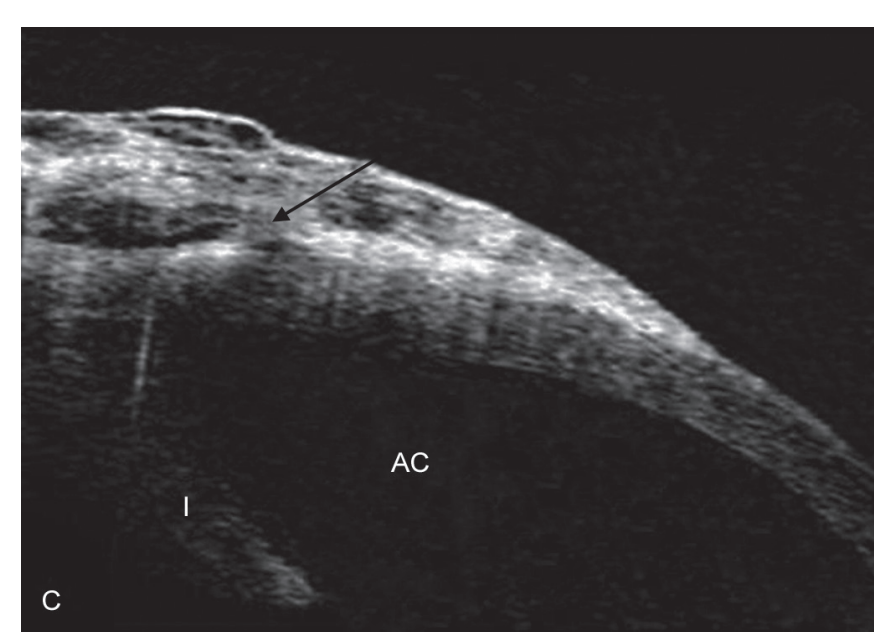

Fig. 3: Filtering blebs: AS-OCT showing elevated functioning filtering blebs. The bleb is moderately elevated and homogeneously spongy with fluid-filled spaces

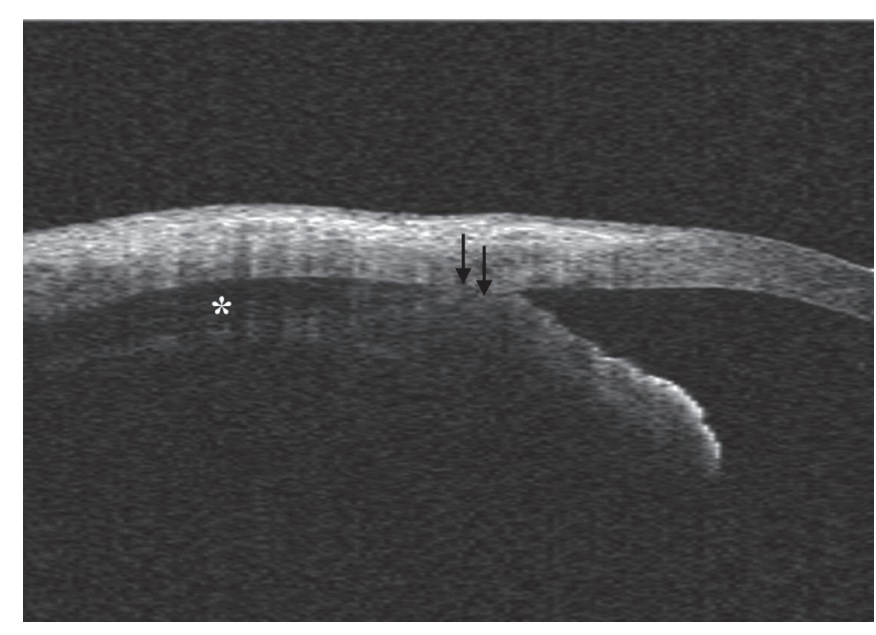

Fig. 4: Cyclodialysis cleft: AS-OCT reveal the separation between the longitudinal muscle of the ciliary body and the scleral spur (arrows). Note the supraciliary effusion (asterisks)

tube inserted into the ciliary sulcus. The anatomic relationships can be assessed, as can compression of the tube at the scleral entry site.

\section{SUMMARY AND CONCLUSION}

The major advantages of the newer devices are the noncontact nature of examination, high scan speed, good repeatability and reproducibility for quantitative and qualitative measurements and cross-sectional visualization of anterior segment structures. Since, ASOCT can visualize entire anterior chamber, all the essential parameters for detection of angle closure/narrow angle can be examined in a single scan. The ASOCT would become an essential tool for screening PAC, making screening programs for PACG more feasible and less doctor-dependent (Leung, Eye 2011). The application of ASOCT has led to a better understanding of anterior segment diseases. It can now be readily quantified making longitudinal follow-ups and assessments possible. The use 


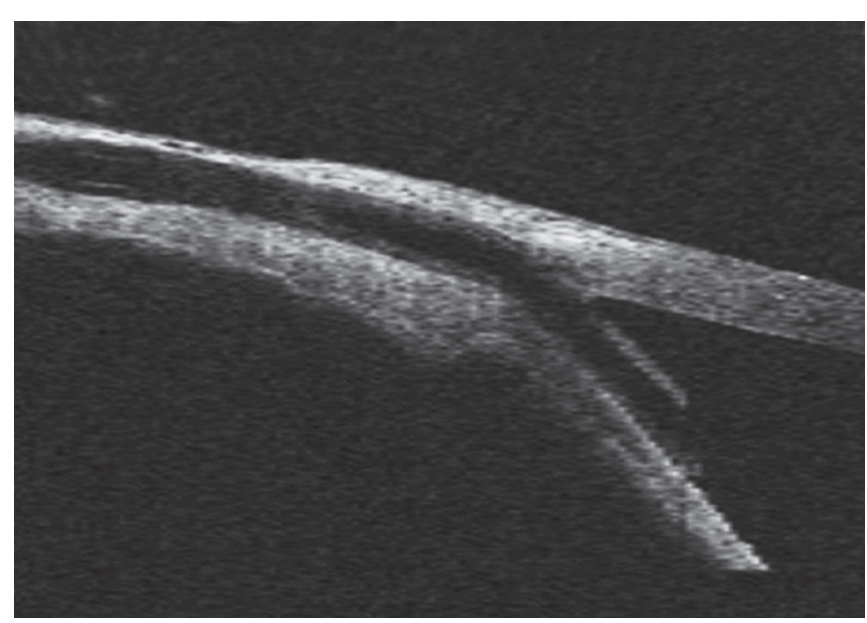

Fig. 5: Glaucoma drainage implant: AS-OCT showing the path of the tube from the anterior chamber

of newer anterior segment imaging devices could well be the start of a new era for ophthalmic diagnosis. With the advent of Fourier domain OCT, the diagnostic capacity of ASOCT has increased many folds. Although still in its preliminary stages, it has the potential to transform ASOCT into a practical and decision-making tool.

\section{REFERENCES}

1. Huang D, Swanson EA, Lin CP, Schuman JS, Stinson WG, Chang W, Hee MR, Flotte T, Gregory K, Puliafito CA, et al. Optical coherence tomography. Science 1991 Nov;254(5035):11781181.

2. Bechmann M, Thiel MJ, Neubauer AS, Ullrich S, Ludwig K, Kenyon KR, Ulbig MW. Central corneal thickness measurement with a retinal optical coherence tomography device versus standard ultrasonic pachymetry. Cornea 2001 Jan;20(1):50-54.

3. Leung CK, Chan WM, Ko CY, Chui SI, Woo J, Tsang MK, Tse RK. Visualization of anterior chamber angle dynamics using optical coherence tomography. Ophthalmology 2005 Jun;112(6):980-984.

4. Leung DY, Lam DK, Yeung BY, Lam DS. Comparison between central corneal thickness measurements by ultrasound pachymetry and optical coherence tomography. Clin Experiment Ophthalmol 2006 Nov;34(8):751-754.

5. Madgula IM, Kotta S. Stratus optical coherence tomogram III: A novel, reliable and accurate way to measure corneal thickness. Indian J Ophthalmol 2007 Jul-Aug;55(4):301-303.

6. Wirbelauer C, Scholz C, Hoerauf H, Engelhardt R, Birngruber $\mathrm{R}$, Laqua H. Corneal optical coherence tomography before and immediately after excimer laser photorefractive keratectomy. Am J Ophthalmol 2000 Dec;130(6):693-699.

7. Wong AC, Wong CC, Yuen NS, Hui SP. Correlational study of central corneal thickness measurements on Hong Kong Chinese using optical coherence tomography, Orbscan and ultrasound pachymetry. Eye (Lond) 2002 Nov;16(6):715-721.

8. Dorairaj S, Liebmann JM, Ritch R. Quantitative evaluation of anterior segment parameters in the era of imaging. Trans Am Ophthalmol Soc 2007;105:99-108.
9. Nolan WP, See JL, Chew PT, Friedman DS, Smith SD, Radhakrishnan S, Zheng C, Foster PJ, Aung T. Detection of primary angle closure using anterior segment optical coherence tomography in Asian eyes. Ophthalmology 2007 Jan;114(1):33-39.

10. Hangai M, Ojima $Y$, Gotoh N, Inoue R, Yasuno $Y$, Makita S, Yamanari M, Yatagai T, Kita M, Yoshimura N. Three-dimensional imaging of macular holes with high-speed optical coherence tomography. Ophthalmology 2007 Apr;114(4): 763-773.

11. Ojima Y, Hangai M, Sasahara M, Gotoh N, Inoue R, Yasuno Y, Makita S, Yatagai T, Tsujikawa A, Yoshimura N. Threedimensional imaging of the foveal photoreceptor layer in central serous chorioretinopathy using high-speed optical coherence tomography. Ophthalmology 2007 Dec;114(12):2197-2207.

12. Srinivasan VJ, Wojtkowski M, Witkin AJ, Duker JS, Ko TH, Carvalho M, Schuman JS, Kowalczyk A, Fujimoto JG. Highdefinition and 3-dimensional imaging of macular pathologies with high-speed ultrahigh-resolution optical coherence tomography. Ophthalmology 2006 Nov;113(11): 2054-2014.

13. Foster PJ, Johnson GJ. Glaucoma in China: how big is the problem? Br J Ophthalmol 2001 Nov;85(11):1277-1282.

14. Spaeth GL, Aruajo S, Azuara A. Comparison of the configuration of the human anterior chamber angle, as determined by the Spaeth gonioscopic grading system and ultrasound biomicroscopy. Trans Am Ophthalmol Soc 1995;93:337-347.

15. Spaeth GL, Azuara-Blanco A, Araujo SV, Augsburger JJ. Intraobserver and interobserver agreement in evaluating the anterior chamber angle configuration by ultrasound biomicroscopy. J Glaucoma 1997 Feb;6(1):13-17.

16. Pavlin CJ, Harasiewicz K, Foster FS. Ultrasound biomicroscopy of anterior segment structures in normal and glaucomatous eyes. Am J Ophthalmol 1992 Apr;113(4):381-389.

17. Ishikawa H, Liebmann JM, Ritch R. Quantitative assessment of the anterior segment using ultrasound biomicroscopy. Curr Opin Ophthalmol 2000 Apr;11(2):133-139.

18. Radhakrishnan S, Goldsmith J, Huang D, Westphal V, Dueker DK, Rollins AM, Izatt JA, Smith SD. Comparison of optical coherence tomography and ultrasound biomicroscopy for detection of narrow anterior chamber angles. Arch Ophthalmol 2005 Aug;123(8):1053-1059.

19. Sakata LM, Lavanya R, Friedman DS, Aung HT, Seah SK, Foster $\mathrm{PJ}$, Aung T. Assessment of the scleral spur in anterior segment optical coherence tomography images. Arch Ophthalmol 2008 Feb;126(2):181-185.

20. Li H, Leung CK, Cheung CY, Wong L, Pang CP, Weinreb RN, Lam DS. Repeatability and reproducibility of anterior chamber angle measurement with anterior segment optical coherence tomography. Br J Ophthalmol 2007 Nov;91(11):1490-1492.

21. Woo EK, Pavlin CJ, Slomovic A, Taback N, Buys YM. U1trasound biomicroscopic quantitative analysis of light-dark changes associated with pupillary block. Am J Ophthalmol 1999 Jan;127(1):43-47.

22. Leung CK, Cheung CY, Li H, Dorairaj S, Yiu CK, Wong AL, Liebmann J, Ritch R, Weinreb R, Lam DS. Dynamic analysis of dark-light changes of the anterior chamber angle with anterior segment OCT. Invest Ophthalmol Vis Sci 2007 Sep;48(9):41164122.

23. Muller M, Dahmen G, Porksen E, Geerling G, Laqua H, Ziegler A, Hoerauf H. Anterior chamber angle measurement with optical coherence tomography: Intraobserver and interobserver variability. J Cataract Refract Surg 2006 Nov;32(11):1803-1808. 
24. Urbak SF. Ultrasound biomicroscopy. I. Precision of measurements. Acta Ophthalmol Scand 1998 Aug;76(4):447-455.

25. Wirbelauer C, Karandish A, Haberle H, Pham DT. Noncontact goniometry with optical coherence tomography. Arch Ophthalmol 2005 Feb;123(2):179-185.

26. Dada T, Sihota R, Gadia R, Aggarwal A, Mandal S, Gupta V. Comparison of anterior segment optical coherence tomography and ultrasound biomicroscopy for assessment of the anterior segment. J Cataract Refract Surg 2007 May;33(5):837-840.

27. Leung CK, Li H, Weinreb RN, Liu J, Cheung CY, Lai RY, Pang CP, Lam DS. Anterior chamber angle measurement with anterior segment optical coherence tomography: A comparison between slit lamp OCT and Visante OCT. Invest Ophthalmol Vis Sci 2008 Aug;49(8):3469-3474.

28. Devereux JG, Foster PJ, Baasanhu J, Uranchimeg D, Lee PS, Erdenbeleig T, Machin D, Johnson GJ, Alsbirk PH. Anterior chamber depth measurement as a screening tool for primary angle-closure glaucoma in an East Asian population. Arch Ophthalmol 2000 Feb;118(2):257-263.

29. Mandell MA, Pavlin CJ, Weisbrod DJ, Simpson ER. Anterior chamber depth in plateau iris syndrome and pupillary block as measured by ultrasound biomicroscopy. Am J Ophthalmol 2003 Nov;136(5):900-903.

30. Baikoff G, Jitsuo Jodai H, Bourgeon G. Measurement of the internal diameter and depth of the anterior chamber: IOLMaster versus anterior chamber optical coherence tomographer. J Cataract Refract Surg 2005 Sep;31(9):1722-1728.

31. Fontana ST, Brubaker RF. Volume and depth of the anterior chamber in the normal aging human eye. Arch Ophthalmol 1980 Oct;98(10):1803-1808.

32. Lee DA, Brubaker RF, Ilstrup DM. Anterior chamber dimensions in patients with narrow angles and angle-closure glaucoma. Arch Ophthalmol 1984 Jan;102(1):46-50.

33. Wang N, Wang B, Zhai G, Lei K, Wang L, Congdon N. A method of measuring anterior chamber volume using the anterior segment optical coherence tomographer and specialized software. Am J Ophthalmol 2007 May;143(5):879-881.

34. Lei K, Wang N, Wang L, Wang B. Morphological changes of the anterior segment after laser peripheral iridotomy in primary angle closure. Eye (Lond) 2009 Feb;23(2):345-350.

35. Avitabile T, Russo V, Uva MG, Marino A, Castiglione F, Reibaldi A. Ultrasound-biomicroscopic evaluation of filtering blebs after laser suture lysis trabeculectomy. Ophthalmologica 1998;212(Suppl 1):17-21.

36. McWhae JA, Crichton AC. The use of ultrasound biomicroscopy following trabeculectomy. Can J Ophthalmol 1996 Jun;31(4):187-191.
37. Munnich S, Lieb WE, Jahn R, Grehn F. Ultrasound biomicroscopy findings in various forms of glaucoma. Ophthalmologe 1995 Aug;92(4):526-530.

38. Labbe A, Dupas B, Hamard P, Baudouin C. In vivo confocal microscopy study of blebs after filtering surgery. Ophthalmology 2005 Nov;112(11):1979-1986.

39. Leung CK, Yick DW, Kwong YY, Li FC, Leung DY, Mohamed S, Tham CC, Chung-chai C, Lam DS. Analysis of bleb morphology after trabeculectomy with Visante anterior segment optical coherence tomography. Br J Ophthalmol 2007 Mar;91(3):340344.

40. Singh M, Chew PTK, Friedman DS, Nolan WP, See JL, Smith SD, Zheng C, Foster PJ, Aung T. Imaging of trabeculectomy blebs using anterior segment optical coherence tomography. Ophthalmology 2007 Jan;114(1):47-53.

41. Ciancaglini M, Carpineto P, Agnifili L, Nubile M, Lanzini M, Fasanella V, Mastropasqua L. Filtering bleb functionality: A clinical, anterior segment optical coherence tomography and in vivo confocal microscopy study. J Glaucoma 2008 JunJul;17(4):308-317.

42. Theelen T, Wesseling P, Keunen JE, Klevering BJ. A pilot study on slit lamp-adapted optical coherence tomography imaging of trabeculectomy filtering blebs. Graefes Arch Clin Exp Ophthalmol 2007 Jun;245(6):877-882.

43. Singh M, See JL, Aquino MC, Thean LS, Chew PT. High-definition imaging of trabeculectomy blebs using spectral domain optical coherence tomography adapted for the anterior segment. Clin Experiment Ophthalmol 2009 May;37(4):345-351.

44. Tominaga A, Miki A, Yamazaki Y, Matsushita K, Otori Y. The assessment of the filtering bleb function with anterior segment optical coherence tomography. J Glaucoma 2010 OctNov;19(8):551-555.

45. Pfenninger L, Schneider F, Funk J. Internal reflectivity of filtering blebs versus intraocular pressure in patients with recent trabeculectomy. Invest Ophthalmol Vis Sci 2011 Apr $14 ; 52(5): 2450-2455$.

\footnotetext{
${ }^{1-6}$ Professor

${ }^{1,2,4-6}$ Department of Ophthalmology and Visual Sciences, Hong Kong Eye Hospital, The Chinese University of Hong Kong, Hong Kong

${ }^{3}$ Department of Ophthalmology, Mayo Clinic, Jacksonville, Florida, USA

Corresponding Author: Syril Dorairaj, Department of Ophthalmology, Mayo Clinic, Jacksonville, Florida, USA, e-mail: dorairaj.syril@mayo.edu
} 